\section{Table Olives: A Vehicle for the Delivery of Bioactive Compounds}

\section{Dimitrios Boskou}

School of Chemistry, Aristotle University of Thessaloniki, Greece

*Corresponding author: Dimitrios Boskou, Professor Emeritus, School of Chemistry, Aristotle University of Thessaloniki, Greece, Tel: 0030 2310-411478; E-mail: boskou@chem.auth.gr

Received date: January 11, 2017; Accepted date: March 27, 2017; Published date: March 31, 2017

Copyright: (c) 2017 Boskou D. This is an open-access article distributed under the terms of the Creative Commons Attribution License, which permits unrestricted use, distribution, and reproduction in any medium, provided the original author and source are credited.

\begin{abstract}
Table olives and olive oil are sources of compounds with important biological properties and essential components of the Mediterranean Diet. For a long period the scientific community focused its attention mainly on the beneficial effects of olive oil on health. The importance of the edible processed fruit was rather overlooked. Table olives contain a large amount of high quality fat, essential amino acids, minerals, vitamins, fiber and a group of minor compounds, which include biophenols and pentacyclic triterpenes. In the last decade an effort is seen in the literature to re-evaluate table olives as sources of bioactive compounds. There is an impressive increase of papers dealing with the composition of processed olives, the effect of variety and processing methods on the level of antioxidants and other minor bioactive constituents, and generally the improvement of healthy features. The information, however, is rather scattered and not all the publications are of the same scientific level. There are many repetitions but also discrepancies and blanks due to difficulties deriving from the complex nature of phenols, the biochemical routes related to lactic acid and other fermenting bacteria and the analytical results, considering the lack of standard methods for the quantitation of small or minute quantities of bioactive compounds The present review discusses table olives as a vehicle for the delivery of bioactive compounds. It concentrates mainly on the levels of bioactive compounds in relation to the treatment of olive fruits and the expected healthy features and functionality.
\end{abstract}

Keywords: Table olives; Diet, Bioactive; Olea europaea L.; Glucoside; Phenolics

\section{Introduction}

Table olives are fermented vegetables very popular and largely consumed in the countries surrounding the Mediterranea basin. They are the fruits of the olive tree (Olea europaea L.) that have undergone the pertinent processes, preserved by natural fermentation, heat treatment or other methods They must comply with the descriptions of the types of olives, trade preparations and styles and with the essential composition and quality criteria laid down in the Trade Standard applying to table olives adopted by the International Olive Council Standard for table olives [1]. Fresh olives are picked when green-ripe, turning color or black-ripe, depending on the mode of processing to be used. They are not comestible because of the presence of the bitter glucoside, oleuropein.

Table oils constitute an essential element of the Mediterranean diet and they are a featured ingredient for hundreds of dishes. They are important from a nutritional point of view for the general population in many Mediterranean countries, especially during the long periods of fasting. They are also of vital importance for the Christian orthodox monks and nuns, who consume large quantities of olives. In other cases organoleptic and other properties are taken into consideration and not the nutritional importance, for example when olives are used as a piece of decoration in a dish, when used in condiments for pasta and pizza or when they are lye-cured and darkened by exposure to air and rapid oxidation.

Processing of raw olives aims at eliminating natural bitterness, mainly due to the biter secoiridoid oleuropein and other phenolics, and improving the taste. It is based on soaking in water, brine, dilute alkali, drying by salting and darkening by oxidation. Large scale processors generally use lye treatments which speed up processing. Small and very small-scale producers favor more "natural" methods. The bitter taste of processed table olives depends on the phenolic compounds present after the processing and it is an important characteristic favored by the consumers. Preparations and styles including procedures based on IOC standards and practices applied for local popular products have been reviewed [2-6].

Many of the health benefits of table olives are related to cardiovascular, respirator, immune, musculoskeletal, nervous and digestive systems. They are associated with fatty acid composition of the lipid fraction and the richness in non-dietary micro-constituents [4,7-11].

For the levels of the latter there are some differences and discrepancies in the literature. This is due to the difference of variety and method of debittering and probably to methods that lead to inaccurate quantifications. This review highlights recent studies and findings related to composition and health benefits expected from the consumption of table olives and the factors influencing the levels of phenolics and other bioactive constituents. Reported values for processed olives were selected mainly from recent, more reliable sources, based on chemical characterization and quantification with modern hyphenated methods that include chemical identification of each peak in the chromatograms.

\section{Nutritional Value of Table Olives}

Table olives provide energy, proteins, carbohydrates and vitamins. The fat content ranges from 100 to $300 \mathrm{~g} / \mathrm{kg}$. They are a good source of oleic acid, a monounsaturated fatty acid. In 2004 the US Food and Drug Administration (FDA) announced the availability of a qualified 
health claim for monounsaturated fat from the olive oil stating that eating 2 tablespoons of olive oil a day is beneficial in reducing coronary heart disease (CHD) (http:/www.fda.gov./dms/qholive/htlm).

Table olives provide also vitamin E (13-52 mg/kg), small quantities of the B-complex (thiamin, niacin, pantothenic acid, vitamin $\mathrm{B}_{6}$ ), betacarotene (pro-vitamin A), important minerals (phosphorous, iron, calcium, magnesium, potassium) and microelements (copper, zinc, manganese). Another important characteristic is the high dietary fiber content. Values reported range from 2.5-5\%. Most preparations have a content $\geq 3 \mathrm{~g} / 100 \mathrm{~g}$ of edible part, so they can be labelled as a source of fiber $[4,7]$.

\section{Bioactive Constituents in Table Olives}

\section{Polar phenols}

In addition to nutrients table olives are rich sources of compounds that are expected to provide health effects beyond the basic nutritional needs. The most important classes of phytochemicals are phenolics but other compounds such as squalene, terpenoids, phytosterols and betacarotene (in small quantities) are also present. Most of them are compounds with unquestionable biological value.

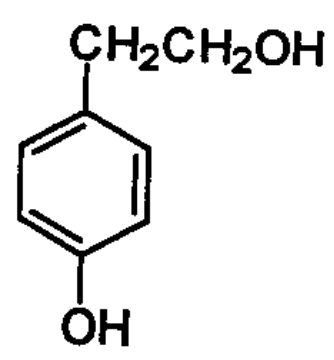

Figure 1A: Structural formula of Tyrosol, an important table olive phenol.

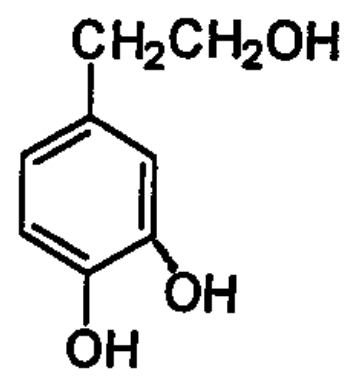

Figure 1B: Structural formula of Hydroxytyrosol.

The major phenolic compounds present in olive fruits are anthocyanins (cyanidin glucosides); flavonols (mainly quercetin-3rutinoside); flavones (luteolin and apigenin glucosides); phenolic acids (hydroxybenzoic, hydroxycinnamic, others); phenolic alcohols (tyrosol, hydroxytyrosol, 3,4-dihydroxyphenylglycol) (Figures 1A and 1B); secoiridoids (oleuropein, demethyloleuropein, ligstroside, nuzhenide) (Figure 1C); verbascoside (caffeoylrhamnosylglucoside of hydroxytyrosol, the main hydroxycinnamic acid derivative found in olive fruits) (Figure 1D), lignans and Oleoside-11-methylester [8-17].<smiles>CC=C1C(OCl)OC=C(C(=O)OC)C1CC(=O)OCCc1ccc(O)c(O)c1</smiles>

Figure 1C: Structural formula of Oleuropein.

The phenolic composition of table olives is different from that of olive fruits since, depending on the method, phenols diffuse in the lime or decompose. The main polar phenols reported to be found in processed olives are hydroxytyrosol, tyrosol, flavonoids (luteolin, apigenin) (Figure $1 \mathrm{E}$ and $1 \mathrm{~F}$ ), anthocyanins (cyanidin-3-O-glucoside and cyanidin-3-O-rutinoside), verbascoside, and phenolic acids [18-22]. Suza and her co-workers [19] and Pereira et al. [20] reported also the presence of luteolin 7-O-glucoside and rutin in different olives from Portugal. Traditionally prepared Throuba Thassos table olives, a Greek table olive variety, have been reported to be rich sources of oleureupein $[21,22]$.<smiles>CC=C1C(OC)OC=C(C(=O)OC)C1CC(=O)OC</smiles>

Figure 1D: Structural formula of Verbascoside.

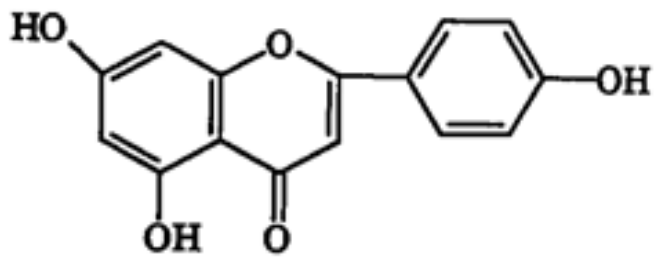

Figure 1E: Structural formula of Apigenin.

Total polar phenols: Blekas et al. [17] and Boskou et al. [18] applied the conventional method Folin-Ciocalteu to samples of commercial table olives from the Hellenic market. Values reported depending on the style and varieties were as high as 1700 expressed in $\mathrm{mg}$ caffeic acid per kg. Higher values were found in Greek-style naturally black olives in brine and Kalamata olives in brine. High concentrations of phenolics were also found in Italian table olives (240-1700 mg caffeic acid/kg edible part) [4]. The analyses carried out by Romero et al. [23] 
on 48 samples of various table olives showed that olives in brine had the highest concentration in total phenols $(1200 \mathrm{mg} / \mathrm{kg})$, whereas oxidized olives had the lowest. Melliou et al. [22] quantified phenols using Ultrahigh-Pressure Liquid Chromatography Triple-Quadrupole Tandem Mass Spectrometry. They reported values below $37 \mathrm{mg} / \mathrm{kg}$ for California-style black ripe olives.

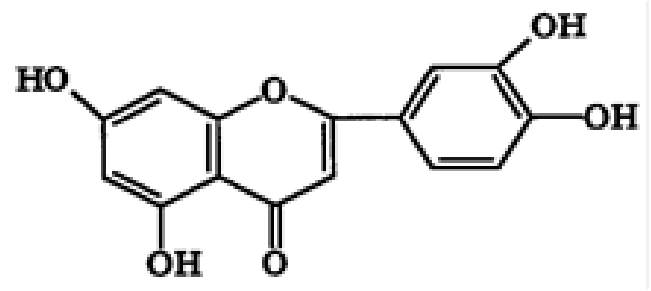

Figure 1F: Structural formula of Luteolin.

Hydroxytyrosol, Tyrosol, glycosides: The level of individual phenols in the treated olives differs significantly from those of fresh olives. The glycosides oleuropein, verbascoside, ligstroside are significantly reduced and can reach quantification limits, depending on the method of processing, cultivar, and initial phenol profile. Losses occur due to the dilution to water and hydrolysis. From the hydrolysis of oleuropein and verbascoside an increase in hydroxytyrosol occurs. The latter becomes the major phenol in processed olives. Values have been reported as high as $760 \mathrm{mg} / \mathrm{kg}$ by Blekas et al. [17] and $1100 \mathrm{mg} / \mathrm{kg}$ by Boskou et al. [18]. Values for tyrosol were found to range from 10-170 $\mathrm{mg} / \mathrm{kg}$ in various table olives styles. Processing according to Spanish style and California style results in products with lower levels of total phenols, hydroxytyrosol and tyrosol. Zoidou et al. [21] studied carefully throumba olives from Thassos, debittered by a traditional Greek mode based on the use of dry salt. These naturally black wrinkled olives may have a level of oleuropein as high as $550 \mathrm{mg} / \mathrm{kg}$ flesh, due to the processing. They are not fermented products but just debittered and this explains why an increased number of phenolic compounds in the flesh remain in their bound forms.

Other minor phenols the presence of which has been confirmed in treated olives are caffeoyl-6'-secologanoside, and comselogoside [24,25]. 3,4-Dihydroxyphenylglycol (DHPG) was also found to be present in the pulp natural table olives from ten different cultivars at levels up to $368 \mathrm{mg} / \mathrm{kg}$ dry weight [26]. The presented data for this antioxidant indicate that natural table olives are a rich source of DHPG.

Differences are observed among various reports even for olives of the same style. Romeo et al. [27] determined rather high values for oleuropein (60-95 mg/kg flesh) and Verbascoside (7-14 mg/kg flesh) in green olives naturally fermented. It is difficult to compare various results reported considering the method of fermentation and postfermentation conditions, the different methods of analysis, the lack of standards, and the different mode of expression of the results ( as gallic acid, or caffeic acid per flesh weight or dry flesh weight). Additional confusion is due to the characterization of all table biophenols as polyphenols. The major phenols in table olives, hydroxytyrosol, tyrosol, oleuropein are not polyphenols. In spite of the difficulties in evaluating the level of bioactive compounds, however, it can be generally concluded that table olives are good sources of biophenols either in their free or in their bound forms.
Oleuropein, and hydroxytyrosol are among nature's most powerful anti-oxidants and their biological role has been a hot topic of research the last 30 years. Together with vitamin $\mathrm{E}$ and carotenoids, they play a vital role fighting against cancer, inflammation, coronary artery disease, degenerative nerve diseases and diabetes. The literature specifically related to their bioaccessibility, absorbability, bioavailability as constituents of table olive phenols is not complete [24] but there is a plethora of publications for the potential health promoting effects of oleuropein, hydroxytyrosol, verbascoside and flavonoids as constituents of olive oil [27-30].

The best-studied antioxidant phytonutrients found in olives are oleuropein and hydroxytyrosol. Their intake is related to LDL cholesterol oxidation, oxidative stress; and protection of nerve cells from oxygen-related damage. The studies are extensive and some health benefits and a protective action against oxidative stress and inflammation are now considered documented. Bioavailability and mechanisms of action reviews have been presented by [31-36]. Accumulated scientific work focuses on oxidation mechanisms, free radical damage, effect on lipoprotein metabolism, inflammation, endothelial dysfunction, and blood pressure. The potential of certain phenols in oncology, chemoprevention, cell-specific cytotoxic and apoptotic effects has been broadly studied and discussed. The importance of hydroxytyrosol in protection of low-density lipoproteins and consequently its implication in the reduction of cardiovascular disease risk has been highlighted by the European Food Safety Authority, concluding that $5 \mathrm{mg}$ of hydroxytyrosol and its derivatives should be consumed daily to reach this effect at physiological level [36].

Modern studies focus on the clarification of molecular mechanisms accounting for the antioxidant, anti-inflammatory, and anticancer properties through gene transcription profiling and nutrigenomic effects that modulate the expression of decease related genes $[31,35,37,38]$.

The evidence showing the multiple benefits of olive phenolic compounds for the aging brain seems to climb rapidly. The neuroprotective effects of these phenols in in vitro and preclinical studies have been recently highlighted by Syed Haris Omar [38].

Flavonoids: Luteolin levels range from a few $\mathrm{mg}$ to $75 \mathrm{mg} / \mathrm{kg}$ flesh [18] depending on the variety and the processing method. Higher concentrations were estimated for Greek-style naturally black olives in brine, Kalamata olives in brine and naturally black olives in dry salt. Luteolin 7-O-glycoside was found in air dried Throumba Thassos olives [22] Apigenin-7-glucoside and rutin were reported as constituents of the polar fraction obtained from naturally fermented green olives [20]. Recently Soufi et al. [39] reported high values of luteolin-7-glucoside, quercetin-3-rutinoside (rutin), and cyanidin-3rutinoside in dry salt processed olives of Algerian varieties.

Lignans: Lignans are phenols found in plants; they are part of the phytoestrogen family, which is known for its health properties. The lignans (+)-1-acetoxypinoresinol, (+)-pinoresinol and syrigaresinol are major components of the phenolic fraction of olive oils $[40,41]$. Lignans are polyphenols found in plants, and they are part of the phytoestrogen family, which is known for its health properties. LópezBiedma et al. [42] reviewed the literature regarding the main lignans found in virgin olive oils and their prominent role in the health effects attributed to virgin olive oils.

Phenolic acids: Small to minute quantities have been reported for processed olives by Boskou and his collaborators [11] who qualified 
and determined with gas chromatography-mass spectroscopy the following phenolic acids and cinnamic acid in five Greek types of table olives: caffeic acid, ferulic acid, p-hydroxy-benzoic acid, p-hydroxyphenylacetic acid, p-hydroxy-phenyl-propanoic acid, protocatechuic acid, p-coumaric acid, cinnamic acid, 3,4-dihydroxy-phenyl-acetic acid and vanilic acid. According to Romero et al. [23] phenolic acids are detected in small quantities in brine processed olives because they are partly metabolized by the microrganisms during the brining period. Romeo et al. [27] based on gas-chromatograpic analysis provided numerical data for small quantities of 4-hydroxybenzoic, chlorogenic (5-O-caffeoylquinic), syringic, vanillic, caffeic 2,4-dihydroxybenzoic, p-coumaric and ferulic acids in naturally fermented green table olives (cv Nocellara etnea).

Phenolic acids are phytochemicals which exhibit a wide variety of biological activities such as antioxidant, anti-inflammatory and many others.

\section{Lipid soluble phenols}

a-Tocopherol values reported for 30 samples of processed olives from the Italian market ranged between 25 and $90 \mathrm{mg} / \mathrm{kg}$ [43]. Samples of of "Alcaparras" Stoned Table Olives from Northeast Portugal showed an average of total tocopherols of $12 \mathrm{mg} / 100 \mathrm{~g}$ of fresh weight, being $\alpha$ tocopherol the most abundant. The other homologues (beta-, gammaand delta-) were found in ppm or sub-ppm quantities [43].

\section{Non-phenolic compounds}

Triterpenic acids and triterpene dialcohols: Maslinic and oleanolic acids are the most abundant triterpenic acids found in olive fruits. Processed olives retain a high level of triterpenic acids although there is diffusion in the brine. During the alkaline treatment oleanolic and maslinic salts are formed which are also diffused. Romero et al. [45] reported levels of triterpenic acids (mainly maslinic and oleanolic) (Figures 2A and 2B) ranging from 460 to $2000 \mathrm{mg} / \mathrm{kg}$ in the flesh of many samples of commercial black and green olives from different varieties. Maslinic and oleanolic acids were quantified in naturally processed Conservolea and Kalamon olives [46]. The natural process did not influence their concentration in the final product. Lower concentrations were determined in alkaline-treated Conservolea olives.<smiles>[C]C1(C)C(O)CCC2(C)C1CCC1(C)C2CC=C2C3CC(C)(C)CCC3(C(=O)O)CCC21C</smiles>

Figure 2A: Structural formula of two triterpenic acids present in Table olives (Oleanolic acid).
Triterpenes present in olives and olive oil are described to present different properties, such as an antioxidant protection, and also antiinflammatory, antitumoral, hepatoprotective, cytotoxic, antidiabetogenic, cardio protective, antihypertensive antibacterial and anti-HIV activities [47-53].

Two other non-dietary microconstituents, the triterpene dialcohols, erythrodiol and uvaol, have been studied for their biological role but their level in treated olives is very small. Values in table olives are not reported because these compounds are co-eluted in the gas chromatography columns with aliphatic alcohols and reported as a whole.<smiles>[Y4]C1(C)CCC2(C(=O)O)CCC3(C)C(=CCC4C5([Y4])CC(O)C(O)C([Y4])(C)C5CCC43C)C2C1</smiles>

Figure 2B: Structural formula of two triterpenic acids present in Table olives (Maslinic acid).

Squalene: 30 samples from the Italian market were analyzed for squalene contents by Sagratini et al. [43], Values reported ranged between 540 and $1600 \mathrm{mg} / \mathrm{kg}$. Squalene has been reported to possess antioxidant properties. In vitro experimental evidence indicates that squalene is a highly effective oxygen-scavenging agent. It is also found to have chemo-preventive action against colon cancer. RamirezTorrest, Gabas-Riverat and Osada [10] have conducted recently a study to explore a proper dose of squalele, a trove of metabolic actions, to be used in a functional food or in the therapy of fatty liver.The authors have discussed their results in relation to the level of squalene in virgin olive oil.

Phytosterols: Fermented olives may contain of $200-520 \mathrm{mg} / \mathrm{kg}$ phytosterols [52]. The main phytosterols in the lipid fraction of table olives are $\beta$-sitosterol and $\Delta 5$-avenasterol followed by campesterol. Epidemiologic and experimental studies suggest that dietary phytosterols, and in particular $\beta$-sitosterol, may offer protection from the most common cancers but the concentration of phytosterols in table olives is low.

Beta-carotene: Beta-carotene is a vitamin A provitamin. Sagratini et al. [43] used a validated solid phase extraction (SPE) and high performance-liquid chromatography (HPLC-DAD) method to analyze 30 table olive samples for beta-carotene. Values ranged from 0.4 to 2.6 $\mathrm{mg} / \mathrm{kg}$.

Cinnamic acid: Cinnamic acid is not a phenol but it is reported as such by many researchers. Romeo et al. [27] reported a level of approx. $8 \mathrm{mg} / \mathrm{kg}$ cinnamic acid in naturally fermented green table olives. 
Boskou et al. [11] found only ppm quantities in different table olives from the Greek market.

\section{Effect of Processing on the Contents of Bioactive Compounds in Table Olives}

The levels of phenolic compounds differ significantly and depend on the cultivar, stage of maturity of the fruit and the mode of processing. These important factors should be taken into consideration in selecting the raw material and the production method in order to obtain a product with increased biological value.

Natural olives (Green olives, olives turning colour or black olives) are placed directly in brine in which they undergo complete or partial fermentation, preserved or not by the addition of acidifying agents. Natural debittering is a complex procedure and not yet fully understood and optimized. Sodium chloride concentration, acetic acid concentration, storage temperature and activity of enzymes are the processing factors that influence the rate the hydrolysis of bitter phenols.

Very recently Ramirez et al. [53] tested a low concentration of sodium chloride and acetic acid and low temperatures for the first two months of fermentation followed by stronger conditions in the rest of the fermentation period. Such advanced techniques may be used to accelerate existing debittering methods and manipulate the level of phenolic compounds in the final product.

Debittering with $\mathrm{NaOH}$ solution causes a significant reduction of total polar phenols and especially glycosides, such as such oleuropein, caused by hydrolytic decomposition to hydroxytyrosol and elenolic acid glycositic derivatives and diffusion in the brine. Chemical and biochemical changes due to the effect of lye and the bacteria during the fermentation in the brine have been described by many authors. Poiana and Romeo [54] measured total phenol depletion during the fermentation period. When the Spanish and California methods are applied the losses are higher since the $\mathrm{NaOH}$ solution brings about more changes compared to losses due to fermentation. Oxidation by aeration for rapid darkening causes additional losses of hydroxytyrosol. This diminution is related to reactions in the presence of iron salts, used as catalysts for colour fixation. As a result, California type olives (artificial ripening) have the lowest content of phenols. Methods for the preparation of Greek-style naturally black olives in brine and partly the Spanish style green olives in brine methods permit generally a higher retention of phenols. The goal of certain recent investigations is to modify the Spanish and California processes in order to minimize the processing period and improve quality attributes of the obtained olives by using one-lye treatment instead of successive treatments [55]. Such techniques reduce the volume of waste waters and energy consumption, and give rise to a product which is richer in bioactive substances.

Spontaneous fermentation processes used to ferment black or green olives are difficult to monitor or control. New technologies propose microbial starters to improve organoleptic characteristics, to ensure the maintenance and/or improvement of healthy features of the product and to produce table olives that are a carrier of microorganisms with probiotics characters [9]. The use of microbial starters as inoculants should be applied with the currently available technology so that in addition to the control of the fermentation process, nutritional and healthy features of the product are maintained.
The fast debittering with $\mathrm{NaOH}$ treatment reduces also the concentrations of triterpenic acids in the flesh because of their solubilisation into alkaline solutions. In contrast, the slow de-bittering during natural fermentation of Greek-style olives had no effect on the content of maslinic or oleanolic acid [8] Tufariello and her co-workers [9] stated that in Greek-style preparations, the fermentation of black table olives driven by selected starter cultures can preserve the triterpenic acid content. The amount of these molecules determined was around 1000-2000 mg/kg olive flesh, much higher than the values observed in extra virgin olive oils These data confirm that certain types of table olives are an appealing food vehicle for the delivery of bioactive compounds.

\section{Future Trends}

The main preparation methods of table olives are known for a long time but they are not yet sufficiently optimized. Table olive are now reevaluated from a nutritional and functional point of view mainly because of the properties of phenolic compounds, triterpenic acids and other phytochemicals with a biological value which is considered unquestionable. As the concentration of these phytochemicals depends on the olive cultivar and processing methods it is expected that future challenges will be to investigate further bioaccessibility and/or bioavailability of metabolites, considering the changes in the bioactive compounds profile that take place during fermentation. More precise information will be expected from analytical studies with validated methods for better evaluation of the level of bioactive constituents in processed olives and from nutritional trials in humans after table olives ingestion.The latter will indicate the potential health promoting role of olives and their contribution in lowering the incidence of several human diseases. Lowering the level of sodium chloride and the coinoculation of yeasts and Lactic Acid Bacteria as a multifunctional starter and a strategy for carrying probiotics by table olives are also open fields for research in the functional food arena.

\section{References}

1. International Olive Council (2004) Trade Standard Applying to Table Olives. Resolution No. RES-2/91-IV/04.

2. Kailis S, Harris D (2007) Producing Table Olives, Landlinks Press/CSIRO Publishing: Australia.

3. Sánchez-Gómez AH, García PG, Navarro LR (2006) Trends in table olives production, Grasas Aceites 57: 86-94.

4. Lanza B (2012) Nutritional and Sensory Quality of Table Olives. In Olive Germplasm. The Olive Cultivation, Table Olive and Olive Oil Industry in Italy, Dr. Innocenzo Muzzalupo (Ed.), Intech 343-372.

5. Boskou D, Camposeo S, Clodoveo ML (2015) Table Olives as Sources of Bioactive Compounds, in Olive and Olive Oil Bioactive Constituents, Boskou D (Ed.), AOCS PRESS, 217-261.

6. Arroyo-Lopez FN, Garcia-Garcia P, Rodrıguez-Gomez F, GarridoFernandez A (2016) Olives: Types and Consumption. In Encyclopedia of Food and Health, Caballero B and Finglas M, (Ed.), Elsevier 4: 167-170.

7. Jimenez A, Rodriguez R, Fernandez-Caro I, Guillen R, FernandezBolanos J, et al. (2000) Dietary fibre content of table olives processed under different European styles: study of physico-chemical characteristics. J Sci Food Agric 80: 1903-1908.

8. Alexandraki V, Georgalaki M, Papadimitriou $\mathrm{K}$, Anastasiou $\mathrm{R}$ Zoumpopoulou G, et al. (2014) Determination of triterpenic acids in natural and alkaline-treated Greek table olives throughout the fermentation process. LWT-Food Sci Technol 58: 609-613.

9. Tufariello M, Mita G, Bleve G (2016) Biotechnology can Improve a Traditional Product as Table Olives in Products from olive tree. Boskou D and Clodoveo ML, (Ed.), Intech 235-260. 
10. Ramírez-Torres A, Gabás-Rivera C, Jesús Osada J (2016) Squalene: A Trove of Metabolic Action. In "Products from Olive Tree", Boskou D and Clodoveo ML, (Ed.), INTECH 2-17.

11. Boskou D (2015) Olive fruits, olive oil and table olives bioactive constituents, Olive and Olive Oil Bioactive Constituents. AOCS PRESS 1-30.

12. Vinha AF, Ferreres F, Silva BM, Valentao P, Gonçalves A, et al. (2005) Phenolic profiles of Portuguese olive fruits (Olea europea L.): Influence of cultivar and geographical origin. Food Chem 89: 561-568.

13. Silva S, Gomes L, Leitão F, Coelho AV, Vilas Boas L (2006) Phenolic Compounds and Antioxidant Activity of Olea europaea L. Fruits and Leaves. Food Sci Tech Int 12: 385-396.

14. Alagna F, Roberto R, Panara F, Caporali S, Urbani S, et al. (2012) Olive phenolic compounds: metabolic and transcriptional profiling during fruit development. BMC Plant Biology 12: 162-192.

15. Bianco A, Uccella N (2000) Biophenolic components of olives. Food Res Intern 33: 475-485.

16. Kanakis P, Termentzi A, Michel T, Gikas E, Halabalaki M, et al. (2013) From Olive Drupes to Olive Oil. An HPLC-Orbitrap-Based Qualitative and Quantitative Exploration of Olive Key Metabolites. Planta Medica 79: 1576-1587.

17. Blekas G, Vassilakis C, Harizanis C, Tsimidou M, Boskou D (2002) Biophenols in Table Olives. J Agr Food Chem 50: 3688-3692.

18. Boskou G, Salta FN, Chrysostomou S, Mylona A, Chiou A, et al. (2006) Antioxidant capacity and phenolic profile of table olives from the Greek market. Food Chem 94: 558-564.

19. Sousa A, Ferreira ICFR, Calhelha R, Andrade PB, Valentao P, et al. (2006) Phenolics and antimicrobial activity of traditional stoned table olives 'alcaparra'. Bioorg Medi Chem 14: 8533-8538.

20. Pereira J, Pereira APG, Fereira IC, Valentao P (2006) Table Olives from Portugal: Phenolic Compounds, Antioxidant Potential, and Antimicrobial Activity. J Agric Food Chem 54: 8425-8431.

21. Zoidou E, Melliou E, Gikas E, Tsarbopoulos A, Magiatis P, et al. (2010) Identification of Throuba Thassos, a Traditional Greek Table Olive Variety, as a nutritional rich source of oleuropein. J Agric Food Chem 58: 46-50.

22. Melliou E, Zweigenbaum JA, Mitchell AE (2015) Ultrahigh-Pressure Liquid Chromatography Triple-Quadrupole Tandem Mass Spectrometry Quantitation of Polyphenols and Secoiridoids in California-Style Black Ripe Olives and Dry Salt-Cured Olives. J Agric and Food Chem 63: 24002405.

23. Romero C, Brenes M, Yousfi K, García P, García A, et al. (2004) Effect of cultivar and processing method on the contents of polyphenols in table olives. J Agric Food Chem 52: 479-484.

24. D’Antuono I, Garbetta A, Ciasca B, Linsalata V, Minervini F, et al. (2016) Biophenols from Table Olive cv Bella di Cerignola: Chemical Characterization, Bioaccessibility, and Intestinal Absorption . J Agric Food Chem 64: 5671-5678.

25. Mantzouridou F, Tsimidou MZ (2011) Microbiological quality and biophenol content of hot air-dried Thassos cv. table olives upon storage. Europ J Lipid Sci Technol 113: 786-795.

26. Rondriguez G, Lama A, Jaramillo S, Fuentes-Alventosa JM, Guillén R, et al. (2009) 3,4-Dihydroxyphenylglycol (DHPG): An Important Phenolic Compound Present in Natural Table Olives. J Agric Food Chem 57: 6298-6304.

27. Romeo FV, De Luca S, Piscopo A, Poiana M (2009) Effects of postfermentation processing on the stabilisation of naturally fermented green table olives (cv Nocellara etnea). Food Chem 116: 873-878.

28. Parvaiz M, Hussain K, Shoaib MG, William G, Tufail M, et al. (2013) A Review: Therapeutic Significance of Olive Olea europaea L. (Oleaceae Family). Global J Pharmacol 7: 333-336.

29. Barbaro B, Toietta G, Maggio R, Arciello M, Tarocchi M, et al. (2014) Effects of the olive-derived polyphenol oleuropein on human health. Int J Mol Sci 15: 18508-15524.
30. Servili M, Sordini B, Esposto S, Urbani S, Veneziani G, et al. (2014) Biological Activities of Phenolic Compounds of Extra Virgin Olive Oil. Antioxidants 3: 1-23.

31. Covas MI, Fitó M, de la Torre MR (2015) Minor Bioactive Olive Oil Components and Health: Key Data for Their Role in Providing Health Benefits in Humans. In Olive and Olive Oil bioactive Constituents. Boskou D, (Ed.), AOCS Press 32: 53.

32. Cicerale S, Conlan XA, Sinclair AJ, Keast RS (2008) Chemistry and Health of Olive Oil Phenolics. Crit Rev Food Scie Nutr 49: 218-236.

33. Fernández-Bolaños JG, Lopez O, López-García MA, Marset A (2012) Biological properties of hydroxytyrosol and irs derivatives in Olive Oil. Constituents, Quality, properties and bioconversions. Boskou D (Ed.), Intech 375-396.

34. Vilaplana-Pérez1 C, Auñón D, García-Flores LA, Gil-Izquierdo A (2014) Hydroxytyrosol and potential uses in cardiovascular diseases, cancer, and AIDS. Front Nutr 1: 18.

35. Ray N, Lam N, Luc R, Bonvino N, Karagiannis TC (2015) Cellular and Molecular Effects of Bioactive Phenolic Compounds in Olives and Olive Oil. In Olive and Olive oil Bioactive Constituents. Boskou D, (Ed.), JAOCS- Press, 54-92.

36. EFSA Panel on Dietetic Products, Nutrition and allergies (NDA) (2011) Scientific opinion on the substantiation of health claims related to polyphenols in olive oil and protection of LDL particles from oxidative damage. EFSA Journal 9: 2033.

37. Piroddi M, Albini A, Fabiani R, Giovannelli L, Luceri C, et al. (2016) Nutrigenomics of extra-virgin olive oil: A Review. Biofactors 43: 17-41.

38. Omar SH (2016) Olive: A therapeutic agent against Alzheimer's disease. 5th European Nutrition and Dietetics Conference, Rome, Italy.

39. Soufi O, Romero C, Motilva MJ, Borrás Gaya X, Louaileche H (2016) Effect of dry salting on flavonoid profile and antioxidant capacity of Algerian olive cultivars. Grasas Aceites 67: e132.

40. Owen RW, Mier W, Giacosa A, Hull WE, Spiegelhalder B, et al. (2000) Identification of Lignans as Major Components in the Phenolic Fraction of Olive Oil. Clin Chem 46: 976-988.

41. Dais P, Boskou D (2009) Detection and quantification of phenolic compounds, in olive oil, olives, and biological fluids. In "Olive oil: minor constituents and health. Boskou D, (Ed.), CRC Press Boca Raton 55-105.

42. López-Biedma A, Sánchez-Quesada C, Delgado-Rodríguez M, José J, Gaforio JJ (2016) The biological activities of natural lignans from olives and virgin olive oils: A review. J Functional Foods 26: 36-47.

43. Sagratini G, Allegrini M, Caprioli G, Cristalli G, Dario Giardina D, et al. (2013) Simultaneous Determination of Squalene, $\alpha$-Tocopherol and $\beta$ Carotene in Table Olives by Solid Phase Extraction and HighPerformance Liquid Chromatography with Diode Array Detection. Food Analyt Methods 6: 5-60.

44. Sousa A, Casal S, Bento A, Malheiro R, Oliveira M, et al. (2011) Chemical Characterization of "Alcaparras" Stoned Table Olives from Northeast Portugal. Molecules 16: 9025-9040.

45. Romero C, García A, Medina E, Ruíz-Méndez MaV, de Castro A, et al. (2010) Triterpenic acids in table olives. Food Chem 118: 670-674.

46. Herrera MD, Rodriguez-Rodriguez R, Ruiz-Gutierrez V (2006) Functional Properties of Pentacyclic Triterpenes Contained in "Orujo" Olive Oil. Current Nutr Food Sci 2: 45-49.

47. Allouche Y, Beltrán G, Gaforio JJ, Uceda M, Mesa MD (2010) Antioxidant and antiatherogenic activities of pentacyclic triterpenic diols and acids. Food Chem Toxicol 48: 2885-2890.

48. Allouche Y, Warleta F, Campos M, Sánchez-Quesada C, Uceda M, et al. (2011) Antioxidant, antiproliferative, and pro-apoptotic capacities of pentacyclic triterpenes found in the skin of olives on MCF-7 human breast cancer cells and their effects on DNA damage. J Agric Food Chem 59: 121-130.

49. Rodriguez-Rodriguez R, Perona JS, Herrera MD, Ruiz-Gutierrez V (2006) Triterpenic compounds from 'orujo' olive oil elicit vasorelaxation in aorta from spontaneously hypertensive rats. J Agric Food Chem 54: 2096-2102. 
Citation: Boskou D (2017) Table Olives: A Vehicle for the Delivery of Bioactive Compounds. J Exp Food Chem 3: 123. doi: 10.4172/2472-0542.1000123

Page 7 of 7

50. Sánchez-Quesada C, López-Biedma A, Warleta F, Campos M, Beltrán G, et al. (2013) Bioactive Properties of the Main Triterpenes Found in Olives, Virgin Olive Oil, and Leaves of Olea Agric. Food Chem 61: 12173-12182.

51. Lozano-Mena G, Sánchez-González M, Juan EM, Planas JM (2014) Maslinic Acid, a Natural Phytoalexin-Type Triterpene from Olives-A Promising Nutraceutical? Molecules 19: 11538-11559.

52. López-López A, Montaño A, Ruíz-Méndez MV, Garrido-Fernández A (2008) Sterols, Fatty Alcohols, and Triterpenic Alcohols in Commercial Table Olives. J Am Oil Chem Soc 85: 253:262.
53. Ramírez E, Medina E, García P, Brenes M, Romero C (2017) Optimization of the Natural Debittering of Table Olives. LWT-Food Sci Technol 77: 308-313.

54. Poiana M, Romeo FV (2006) Changes in chemical and microbiological parameters of some varieties of Sicily olives during natural fermentation. Grasas Aceites 57: 402-408.

55. Romero C, Garcia-Garcia P, Brenes M (2016) Enrichment of Black Ripe Olives in Bioactive Compounds Using a Single Alkali Treatment. J Food Sci 81: C2686-C2691. 